\title{
A Regulação da Saúde Suplementar e o Direito da Pessoa Idosa À Assistência à Saúde
}

\author{
PRIVATE HEALTH REGULATION AND ELDERLY'S \\ RIGHT TO HEALTH ASSISTANCE
}

\author{
Maria Lúcia Lebrão(*) \\ Marília Cristina Prado Louvison ${ }^{(* *)}$ \\ Yeda Aparecida de Oliveira Duarte ${ }^{(* * *)}$
}

\section{INTRODUÇÃO}

Envelhecimento, triunfo ou problema?

Segundo Andy Rooney, “... é um paradoxo que a idéia de ter vida longa agrade a todos, e a idéia de envelhecer não agrade a ninguém." Envelhecer

(*) Professora Titular do Departamento de Epidemiologia da Faculdade de Saúde Pública da Universidade de São Paulo (FSP-USP) e Coordenadora do Estudo SABE — Saúde, Bem-Estar e Envelhecimento. E-mail: <mllebr@usp.br>.

${ }^{(* *}$ Coordenadora Estadual da Área Técnica de Saúde da Pessoa Idosa da Secretaria de Estado da Saúde do Governo do Estado de São Paulo e Doutoranda em Saúde Pública pela Faculdade de Saúde Pública da Universidade de São Paulo (FSP-USP). E-mail: <marilia @ saude.sp.gov.br>. $\left.{ }^{(* *}\right)$ Professora Associada do Departamento de Enfermagem Médico-Cirúrgica da Escola de Enfermagem da Universidade de São Paulo. E-mail:<yedaenf@usp.br>. Recebido em 15.5.08. Aprovado em 30.5.08. 
é uma aspiração natural de todos os integrantes de qualquer sociedade. Para muitos, viver mais representa um triunfo dessas sociedades frente às diferentes adversidades enfrentadas pelos seres humanos nas diversas fases do curso de vida, mas para outros, tal "vitória" significa um pesado ônus para políticas públicas inclusivas e solidárias aos considerados grupos mais vulneráveis da população, pois sabe-se que o processo de envelhecimento pode ser acompanhado por crescentes demandas sociais e de saúde além de maiores custos previdenciários.

Sem dúvida, uma das transformações sociais mais importantes observadas desde a metade do século passado é a maior longevidade das populações, o que vem provocando a necessidade de ajustes nas esferas pública e privada e trazendo alguns questionamentos às sociedades modernas. Embora seja um fenômeno mundial, assume características peculiares nos países em desenvolvimento em especial na América Latina e Caribe onde a população vem envelhecendo rápida e diferenciadamente em um contexto de profundas transformações sociais, incluindo-se os arranjos familiares, o que representa um desafio em termos de proteção social $^{(1)}$.

Segundo Palloni e Pelaez ${ }^{(2)}$, o envelhecimento populacional na América Latina e no Caribe apresenta características únicas, que, combinadas com um contexto institucional instável e um ambiente econômico desfavorável, fazem com que tal processo seja muito mais complicado do que em outras áreas do mundo. Ainda segundo esses autores, nessa região, particularmente entre as coortes que alcançarão os 60 anos no período de 2000-2020, é provável que haja piores distribuições do estado de saúde do que aquelas observadas entre pessoas idosas de outros lugares, mesmo se as desigualdades relevantes nas condições socioeconômicas forem controladas. Caso isso se confirme (e há evidências que reforçam essa hipótese), o processo de envelhecimento nessa região será caracterizado não apenas por uma velocidade e um aumento sem precedentes, mas, também, por um largo potencial de demandas por serviços de saúde.

No entanto, longe de ser entendido como um problema, o envelhecimento populacional representa um triunfo do desenvolvimento social e da saúde pública para o qual as políticas públicas devem ser reorganizadas ${ }^{(3)}$.

(1) CAMARANO, Ana Amélia (Org.). Os novos idosos brasileiros muito além dos 60 ? Rio de Janeiro: IPEA, 2004. 594 p.

(2) PALLONI, Alberto; PELAEZ, Martha. Histórico e natureza do estudo. In: LEBRÃO, Maria Lúcia; DUARTE, Yeda Aparecida de Oliveira. SABE — Saúde, Bem-Estar e Envelhecimento: o Projeto SABE no Município de São Paulo: uma abordagem inicial. Brasília: Organização Pan-Americana da Saúde, 2003. p. 15-32.

(3) KICKBUSH I. Foreword. In: EBRAHIM Saul; KALACHE, Alexandre. Epidemiology in old age. London: BMJ, 1996. 316 p. 
Para compreender tais questionamentos à luz da realidade brasileira, cabe considerar alguns tópicos. Em primeiro lugar, ressalta-se a alta velocidade do processo de envelhecimento em nosso país. De fato, a população brasileira vem sofrendo, desde o início da década de 60 , um acentuado processo de envelhecimento. Desde essa época, observa-se a queda das taxas de fecundidade que começaram a estreitar progressivamente a base de nossa pirâmide populacional. Projeções feitas num período de 60 anos, 1960 a 2020, indicam uma taxa de crescimento da população idosa da ordem de $760 \%$ demonstrando que, enquanto a população em geral aumentará cinco vezes, a população idosa aumentará quinze. De cerca de 7 milhões de pessoas com 60 anos e mais em 1980, passou-se para aproximadamente 11 milhões, em 1991, com perspectivas de 32 a 33 milhões para o ano de 2025. O censo de 1991 já indicava a proporção de $7,3 \%$ de idosos em relação à população recenseada o que, segundo a Organização Mundial de Saúde, classifica o Brasil como um país estruturalmente envelhecido uma vez que sua taxa de indivíduos com 60 anos e mais ultrapassa $7 \%$ do total de sua população. Indicava, também, o crescimento expressivo do número de idosos com 80 anos e mais que passaram de 593 mil em 1980 para pouco mais de um milhão em 1991, representando 10,6\% do grupo populacional de 60 anos e mais. No censo de 2000 , essa proporção aumentou para $8,6 \%$ representando aproximadamente 14,5 milhões de pessoas com 60 anos e mais ${ }^{(4)(5)(6)}$.

Essa mudança no perfil demográfico é acompanhada por alterações nos padrões epidemiológicos que podem ser compreendidas como as principais modificações, a longo prazo, dos padrões de morbidade, invalidez e morte que caracterizam uma população específica. No Brasil, o processo de transição epidemiológica não ocorreu da mesma forma que na maioria dos países industrializados. Observa-se um processo não unidirecional, marcado pelo predomínio das doenças crônicas não transmissíveis e pela reintrodução de doenças como dengue, febre amarela, cólera e o recrudescimento de outras, como malária, hanseníase e leishmaniose. Soma-se a isto a situação epidemiológica contrastante das diferentes regiões. Essa associação de fatores causa um grande impacto na utilização de serviços de saúde e, conseqüentemente, nos custos associados a esses. Esses últimos também são influenciados pela incorporação de altas tecnologias, cuja expansão na área de saúde caminha numa velocidade muito intensa e cujo uso indiscriminado não é inócuo nem para os sistemas de saúde, nem para as pessoas. É nesse contexto que se enquadra o envelhecimento da população

(4) CAMARANO, Ana Amélia (Org.), op. cit.

(5) CHAIMOVICZ, F. A saúde dos idosos brasileiros às vésperas do século XXI: problemas, projeções e alternativas. Revista de Saúde Pública, São Paulo, v. 31, n. 2, p. 184-200, 1997.

(6) PALLONI, Alberto; PINTO-AGUIRRE Guido; PELAEZ, Martha. Demographic and health conditions of ageing in Latin America and the Caribbean. International Journal of Epidemiology, n. 31, p. 762-771, 2002. 
brasileira que, longe de ser visto como um problema, deve ser encarado com planejamento e responsabilidade ${ }^{(7)(8)}$.

Ao tratar da população idosa brasileira, fala-se de um segmento populacional muito heterogêneo. Dele fazem parte, desde pessoas com total autonomia, capazes de contribuir para o desenvolvimento econômico e social e que desempenham importantes papéis no contexto familiar, até aquelas que são incapazes de desempenhar de forma independente suas atividades cotidianas e, muitas vezes, sem nenhum rendimento próprio( ${ }^{(9)}$.

Sabe-se que o envelhecimento é acompanhado de vulnerabilidades, encerramento da atividade econômica, perda de alguns papéis sociais e aquisição de outros, alterações na rede de suporte social, bem como surgimento ou agravamento de doenças crônicas não transmissíveis. Essas transformações e alterações são diferenciadas por sexo, grupo social, cor/ raça, local de moradia, entre outros. As condições de vida dessa população estão, ainda, relacionadas com suas capacidades natas, suas capacidades adquiridas no transcorrer da vida e com a inter-relação entre as duas e sua interface com as facilidades ou dificuldades do meio em que habitam, uma vez que os idosos não vivem isolados e o seu bem-estar está intimamente ligado ao da sociedade como um todo. Tais diferenças podem, no entanto, ser minimizadas pelo implemento de políticas públicas adequadas ${ }^{(10)(11)}$.

Nossa sociedade insiste em não perceber que envelheceu e, apesar de desenvolver uma legislação mais inclusiva para diversos segmentos populacionais, avançou pouco na análise e na proteção das necessidades dos idosos. Conforme questionado por Braga(12), "será essa lacuna jurídica um sinal de que, com o passar dos anos, o idoso deixa de fazer parte ativa da família, relegando-se este apenas ao papel de esperar pela morte e transmissão de seus bens para ver-se de novo lembrado pelos seus códigos? Seus únicos direitos em vida passam a ser apenas os de cunho previdenciário?" É óbvio que não, continua a autora, pois, “... se o idoso continua sendo parte da família, por meio dela deve continuar inserido na sociedade. Seus direitos básicos não devem ser diferenciados dos demais, pois esta é uma das maiores formas de discriminação em que podemos incorrer".

Assim, o Estatuto do Idoso foi criado considerando que os direitos de uma pessoa não se modificam na medida em que ela envelhece e, portanto, não podem e nem devem ser expropriados tendo por base um critério etário.

(7) CHAIMOVICZ, F., op. cit.

(8) MURRAY, C. J, LOPEZ A. D. Global mortality, disability, and the contribution of risk factors:

Global Burden of Disease Study. Lancet, v. 350, n. 9071, p.144, 1997.

(9) CAMARANO, Ana Amélia (Org.), op. cit.

(10) Id. Ibid.

(11) LLOYD-SHERLOCK P. Ageing, development and social protection: a research agenda. UNRISD Meeting on Ageing, Development and Social Protection, 2002. 
Longe de ser protecionista ou paternalista, ele visa preservar a identidade do idoso como cidadão, independentemente de sua idade cronológica, e ser um mecanismo eficiente de adequação da sociedade que precisa ser conduzida a reconhecer a pessoa idosa como alguém socialmente ativo e capaz, pois, se ela o exclui, não terá como refletir suas necessidades nas leis que faz promulgar e cumprir. É, assim, necessário que essa mesma sociedade possa absorver esse novo paradigma, o do envelhecimento, colocando entre seus princípios o respeito ao idoso no sentido mais amplo possível, de forma a atender inequívoca e plenamente ao inciso III do art. 1ำ da Constituição Federal de 1988 “... A República Federativa do Brasil ... constitui-se em Estado Democrático de Direito e tem como fundamentos: (...) III — a dignidade da pessoa humana"(13).

Segundo Cain $^{(14)}$, uma sociedade que proporcionasse aos cidadãos mais velhos o tratamento e a consideração dispensada aos adultos, eliminaria os estatutos jurídicos especiais para os idosos e lhes garantiria o direito à igualdade, considerada um dos "direitos humanos", por ser natural, inata, impostergável, anterior ao Estado e inerente à natureza livre do homem. Assim considerando, o tratamento diferenciado aos idosos determinado pelo Estatuto do Idoso, visa garantir a eles os mesmos direitos assegurados aos demais cidadãos que ainda não envelheceram e, por essa razão, não constitui nenhuma lesão ao princípio de igualdade.

O Estatuto do Idoso foi transformado em lei em $1^{\circ}$ de outubro de 2003 (Lei n. 10.741) e entrou em vigor em $1^{\circ}$ de janeiro de $2004^{(15)}$. Assim como outras legislações existentes em nosso meio (Estatuto da Criança e do Adolescente, Código de Defesa do Consumidor etc.), a finalidade do Estatuto do Idoso é dar maior proteção a um grupo vulnerável da sociedade, no caso, as pessoas com 60 anos e mais. Tem por objetivo garantir os direitos fundamentais e a cidadania dos idosos, visando assegurar seus direitos à vida, saúde, habitação, alimentação, convivência familiar e comunitária, profissionalização e trabalho, educação, cultura, esporte e lazer, previdência e assistência judiciária, além de assistência jurídica ${ }^{(16)(17)}$.

A questão da saúde é tratada no Capítulo IV, arts. 15 a 25. No art. 15, "é assegurada a atenção integral à saúde do idoso, por intermédio do Sistema

(12) BRAGA, Pérola Melissa V. Direitos do idoso de acordo com o Estatuto do Idoso. São Paulo: Quartier Latin, 2005. 287 p.

(13) BRAGA, Pérola Melissa V., op. cit.

(14) CAIN, Leonard. Direitos do homem e direitos das pessoas idosas. XI Congresso Internacional de Gerontologia, Roma-Itália, 1984. In: FERNANDES, Flávio da Silva. As pessoas idosas na legislação brasileira. São Paulo: LTr, 1997. p. 22.

(15) BRASIL. Lei n. 10.741, de 1o de outubro de 2003. Estatuto do Idoso.

(16) BRAGA, Pérola Melissa V. op. cit.

(17) LAZZARINI, Marilena (Org). IDEC — Instituto Brasileiro de Defesa do Consumidor. Estudo sobre a aplicação do Estatuto do Idoso aos planos de saúde: a questão dos reajustes por mudança de faixa etária. São Paulo: IDEC, 2006. 
Único de Saúde (SUS) ...”, e no § 3 trata da saúde suplementar ao proibir a discriminação do idoso em razão de sua idade para cobrança de valores diferenciados nos planos de saúde. Nesse sentido, o amparo legal do direito à saúde dos idosos reporta-se à base legal do SUS que, por meio da Constituição de 1988 e das Leis orgânicas ns. 8.080 e 8.142/90, instituiu uma política pública de bem-estar social, de direito universal e igualitário. 0 direito à saúde suplementar privada, também previsto na Constituição, é garantido ao idoso, livrando-o da discriminação e da segregação por preços abusivos, baseados em seu maior risco de utilização. Tal medida foi necessária para coibir uma série de abusos e ilegalidades que eram, e ainda são, praticados por esses planos que costumam se justificar alegando que a elevação dos custos decorre do fato de que, nas idades mais avançadas, os idosos utilizam os serviços de saúde com maior freqüência que os mais jovens ${ }^{(18)(19)}$.

Desde que entrou em vigor, o Estatuto do Idoso gerou uma controvérsia quanto a sua aplicabilidade: poderia ele ser aplicado aos contratos, relacionados à saúde suplementar, assinados antes de sua entrada em vigor? O Estatuto deveria ser aplicado apenas aos contratos que fossem assinados depois de $1^{\circ}$ de janeiro de $2004 ?^{(20)}$

Há posições defendendo as duas questões. A Agência Nacional de Saúde Suplementar (ANS), responsável pela regulação dos planos de saúde, opta pela segunda, desfavorável ao consumidor. O Instituto Brasileiro de Defesa do Consumidor (IDEC) defende a primeira. Já a Justiça, tem decisões em ambos os sentidos não tendo ainda sido consolidado nenhum deles ${ }^{(21)}$.

Para poder compreender melhor essa polêmica faz-se necessário analisar a participação do idoso no setor suplementar de saúde, tanto com relação à cobertura quanto à utilização dos serviços. O setor privado consome, proporcionalmente, muito mais recursos e a população idosa também, fazendo da análise da utilização de serviços de saúde por idosos na saúde suplementar, uma prioridade inclusive no sentido de estimativa de riscos. No entanto, é importante salientar que essa desvantagem sob o ponto de vista do mercado precisa ter amparo na proteção legal e demanda cuidado da regulação pública no sentido de garantir qualidade da atenção à saúde disponibilizada a esse idoso.

Várias alternativas ao atual modelo de utilização de serviços e custo da área da saúde vêm sendo discutidas nos setores público e privado. A lógica da demanda espontânea e o modelo centrado no médico, no medicamento, no hospital e na incorporação tecnológica desmedida, muitas

(18) BRAGA, Pérola Melissa V., op. cit.

(19) SIQUEIRA, Luiz Eduardo Alves de. Estatuto do idoso de A a Z: idéias e letras. São Paulo, 2004. $238 \mathrm{p}$.

(20) LAZZARINI, Marilena (Org). op. cit.

(21) Id. Ibid. 
vezes iatrogênica para o idoso, medicaliza a velhice e institucionaliza o cuidado. O desafio é o de trazer o idoso para o centro do cuidado, com a implantação do que se denomina atenção gerontológica global e gestão do cuidado ${ }^{(22)}$.

O Pacto pela Saúde do SUS coloca a atenção à saúde do idoso como uma de suas prioridades ${ }^{(23)}$. Discute ainda, a necessidade de avançar na implantação do princípio da integralidade da rede de atenção à pessoa idosa, otimizando as linhas de cuidados integrais à saúde. A Política Nacional de Saúde da Pessoa Idosa reeditada em 2006 ${ }^{(24)}$ coloca como principal paradigma a manutenção da capacidade funcional do idoso e a atenção básica na centralidade do cuidado visando à identificação de riscos e priorização dos cuidados aos idosos frágeis ou em processo de fragilização.

Na Saúde Suplementar, a gestão do cuidado integrado em rede para condições crônicas, preconizado pela $\mathrm{OMS}^{(25)}$, vem sendo alvo de discussão. Essa questão tem por princípio básico a obtenção de maior resolubilidade do sistema na atenção às necessidades de saúde da população, por meio da construção de uma rede eficaz e eficiente (cadeia de agregação de valor) que coloca a saúde como um valor fundamental a ser alcançado via integração dos melhores resultados e não apenas da minimização dos custos. Esse princípio se contrapõe-se ao que hoje é praticado, que se caracteriza pela pulverização e isolamento dos serviços que, ao final do processo, trazem como resultado o que se denomina "soma zero", ou seja, muitos profissionais envolvidos de forma desintegrada, numerosos exames solicitados e, por vezes, desnecessários, tempo elevado entre a inserção do idoso no sistema e o desfecho final, custos altíssimos e resultados ineficientes e, por vezes, não resolutivos.

Nos Estados Unidos, o Sistema Público de Saúde (Medicare), assim como outros sistemas de saúde com foco na população idosa, já vem trabalhando com modelos mais voltados aos cuidados ambulatoriais ou domiciliares.

O estudo Saúde, Bem estar e Envelhecimento (SABE) - inquérito de base populacional de idosos - verificou que, em 2000, 40,4\% dessa

(22) DUARTE, Yeda Aparecida de Oliveira; LEBRÃO, Maria Lúcia. O cuidado gerontológico: um repensar sobre a assistência em gerontologia. In: PESSINI, Leocir. Bioética e envelhecimento. São Paulo: Loyola, 2007.

(23) BRASIL. Ministério da Saúde. Secretaria Executiva. Departamento de Apoio à Descentralização. Coordenação-Geral de Apoio à Gestão Descentralizada. Diretrizes Operacionais dos Pactos pela Vida, em Defesa do Sistema Único de Saúde — SUS e de Gestão. Brasília, 2006.

(24) BRASIL. Ministério da Saúde. Portaria GM n. 2.528, de 19 de outubro de 2006 - Política Nacional de Saúde da Pessoa Idosa - PNSI.

(25) ORGANIZAÇÃO MUNDIAL DE SAÚDE. Cuidados inovadores para condições crônicas: componentes estruturais de ação: relatório mundial. Brasília: Organização Mundial da Saúde, 2003. 
população estava coberta por planos da saúde suplementar, sendo que 35,5\% dos entrevistados referiram ter Plano de Saúde Privado, resultado esse que variou com a escolaridade, passando de $28,6 \%$ entre os menos ou nada escolarizados para $61,7 \%$ entre os de escolaridade mais alta. Esse último grupo também referiu maior cobertura $(26,1 \%)$ de outros seguros de saúde que incluem, por exemplo, as autogestões públicas $(9,1 \%$ no total) e segurosaúde privado $(6,6 \%)^{(26)}$.

Em 2006, em um novo momento do estudo, agora de desenho longitudinal, observou-se que $53 \%$ da população idosa referiu estar coberta pela saúde suplementar, sendo $66 \%$ por planos individuais, cujo pagamento, em $47,6 \%$ das vezes, era realizado pelo próprio idoso. Esse incremento pode indicar a necessidade de possuir um plano alternativo ao SUS, em função do aumento das suas demandas de saúde e das dificuldades encontradas para acessar os serviços de que necessita. Pode também representar uma maior proteção da sociedade às pessoas idosas que, com uma melhoria na renda e a adequação da legislação (Estatuto do Idoso), permitiu, de fato, menor discriminação e maior e melhor acesso à saúde suplementar por esse grupo, quando desejado.

$\operatorname{Veras}^{(27)}$ analisando a cobertura e utilização dos serviços de saúde pela população idosa, com ênfase no setor privado, por meio dos dados do Suplemento de Saúde da Pesquisa Nacional por Amostra de Domicílios (PNAD) de 1998 e 2003 e também pelos disponibilizados pela Agência de Saúde Suplementar (TabNet), observou um aumento da cobertura pelo setor de medicina suplementar de 26,9\% para 29,4\% (1998 e 2003 respectivamente), representando aproximadamente, 5 milhões de brasileiros idosos, concentrando as maiores coberturas nas faixas etárias mais elevadas (70 anos e mais). Verificou, ainda, uma associação positiva entre cobertura e renda familiar o que faz com que os planos de saúde introduzam no sistema brasileiro de saúde um elemento de desigualdade social no acesso e na utilização dos serviços de saúde, porque cobrem, majoritariamente, o segmento populacional de maior renda que, por sua vez, utiliza mais os serviços quando comparados aos pacientes SUS-dependentes, reconhecidamente menos saudáveis, trazendo assim grandes desafios para o setor.

A base referencial do processo regulatório da Saúde Suplementar no Brasil está amparada na Lei n. 9.656/98 que disciplina os Planos de Saúde

(26) CESAR, Chester Luís Galvão; PASCHOAL, Sérgio Márcio Pacheco. Uso dos serviços de saúde. In: LEBRÃO, Maria Lúcia; DUARTE, Yeda Aparecida de Oliveira. SABE - Saúde, Bem-estar e Envelhecimento: o Projeto SABE no município de São Paulo: uma abordagem inicial. Brasília: Organização Pan-Americana da Saúde, 2003.

(27) VERAS, Renato; PARAHYBA, Maria Isabel. O anacronismo dos modelos assistenciais para os idosos na área da saúde: desafios para o setor privado. Cadernos de Saúde Pública, Rio de Janeiro, v. 23, n.10, p. 2479-2489, out. 2007. 
e na Lei n. 9.961/00 que cria a Agência Nacional de Saúde Suplementar (ANS), como uma autarquia especial vinculada ao Ministério da Saúde, com a missão de promover a defesa do interesse público na assistência suplementar à saúde pela regulação e fiscalização do setor, das relações das operadoras setoriais com prestadores de serviços de saúde e com usuários de planos de saúde, para o desenvolvimento das ações de saúde no país ${ }^{(28)}$.

A regulamentação proibiu a seleção de risco e os limites de internação, possibilitou reajustes controlados, definiu e limitou carências e apontou para um modelo de atenção com ênfase nas ações de promoção à saúde e prevenção de doenças, na implementação de sistemas de informações como insumo estratégico, contratos mais transparentes e processo global de qualificação. Esse movimento, em muitas situações, divide a sociedade entre exigir serviços privados melhores, como direito do consumidor, e apoiar as operadoras de saúde, setor regulado, nas suas críticas de encarecimento e conseqüente inviabilização do setor de saúde suplementar.

Esse é um processo recente no sistema público brasileiro e muitas ações da ANS envolveram polêmicas entre os vários interesses e atores do processo regulatório, como a política de ressarcimento ao SUS, a necessidade de adaptação dos planos a uma nova lógica de custos razoáveis, a coleta de dados mediante padronização através da TISS - Troca de Informações em Saúde Suplementar - que exige o código da Classificação Internacional de Doenças (CID) nos impressos de fluxo ambulatorial e a mais recente regulamentação de ampliação do rol, principalmente no sentido de incorporar ações preventivas e multiprofissionais.

Ampliação de direitos e exigência de qualidade vêm sempre acompanhadas de demandas do setor regulado no sentido de repassar os custos para o consumidor final, sendo necessários melhores pactos com a sociedade para qualificar o processo regulatório.

Com relação à faixa etária, os riscos de adoecimento e utilização de serviços aumentam conforme o avançar da idade e impactam diretamente no custo dos planos de saúde, historicamente repassados aos preços praticados ao consumidor. Uma sociedade que envelhece, e tem esse setor regulado na lógica do bem-estar social, precisa solidarizar-se com a população de idosos e dividir esse ônus, nem sempre bem aceito. Alguns autores preocupam-se com a fuga cada vez maior dos jovens dos planos de saúde, que contribuem mais do que usufruem, tornando esse negócio cada vez mais impraticável, considerando seu alto risco.

(28) BRASIL. Agência Nacional de Saúde Suplementar. Planos de saúde: conheça seus direitos. Reajuste de mensalidade: Conceitos básicos, reajuste por variação de custos, reajuste por mudança de faixa etária. 2. ed, Rio de Janeiro: ANS, 2005. 
É conhecido o incremento de gastos em saúde no último ano de vida. O mercado imperfeito da saúde — com assimetria de informações, tendência à seleção de riscos e o chamado risco moral, risco da sobre-utilização em função da disponibilidade - é um espaço onde a regulação é mandatória e a garantia do direito de populações mais vulneráveis e fragilizadas, como os idosos, condição absoluta.

O sistema público de saúde também sofre o impacto da mobilização da sociedade na decisão de contribuir para o sistema de saúde suplementar, pois tem uma rede de serviços de saúde que atua em ambos os sistemas, de difícil regulação interna ao SUS. Além disso, um sistema de saúde privado, pouco resolutivo, onde as coberturas não são garantidas e as necessidades não são satisfeitas, também afugenta a população. Essa pode, eventualmente, identificar um benefício maior em utilizar o serviço público sempre que possível e manter reservas para eventualidades não satisfeitas pelo mesmo, opção para o idoso bastante perigosa, que assume o risco do elevado e crescente custo da saúde.

Na interpretação da ANS do art. 15, § 3ำ do Estatuto do Idoso, este só deve ser aplicado aos contratos firmados a partir de sua entrada em vigor (1‥ de janeiro de 2004). Para os contratos assinados antes dessa data, permanecem as regras de reajuste válidas à época da contratação. Assim, ficam vedados os reajustes para as pessoas com 60 anos ou mais que assinarem contrato após essa data, o mesmo não se aplicando aos contratos anteriores. Em decorrência dessa interpretação, passaram a existir três situações de reajuste por mudança de faixa etária, de acordo com a data de contratação do plano de saúde ${ }^{(29)(30)}$.

1. Planos de saúde antigos: planos contratados antes de 2 de janeiro de 1999 (quando entrou em vigor a Lei dos Planos de Saúde - Lei n. 9.656/ 98) para os quais não há nenhuma regulamentação dispondo sobre as idades e percentuais de aumento por mudança de faixa etária. Os reajustes devem estar previstos e expressos claramente no contrato ou em seus anexos. $\mathrm{Na}$ ausência de previsão contratual, a ANS entende que ela pode autorizar o reajuste por mudança de faixa etária ${ }^{(31)}$.

2. Planos de saúde novos: planos contratados a partir de 2 de janeiro de 1999 (já sob tutela da Lei n. 9.656/98) para os quais há regulamentação quanto às faixas etárias em que poderão incorrer os reajustes os quais deverão ter seus percentuais estabelecidos no contrato. Caso isso não ocorra, o

(29) BRASIL. Agência Nacional de Saúde Suplementar. Planos de saúde: conheça seus direitos. Reajuste de mensalidade: Conceitos básicos, reajuste por variação de custos, reajuste por mudança de faixa etária, cit.

(30) LAZZARINI, Marilena (Org).. op. cit.

(31) LLOYD-SHERLOCK P.. op. cit. 
reajuste é caracterizado como prática abusiva e é, assim, ilegal. Para o aumento por mudança de faixa etária há duas regras ${ }^{(32)}$ :

a) contratos firmados entre janeiro de 1999 e dezembro de 2003: O Conselho de Saúde Suplementar (CONSU), mediante a Resolução n. 06/98, estabeleceu que os aumentos podem ocorrer em sete faixas etárias 0 a 17 anos, 18 a 29 anos, 30 a 39 anos, 40 a 49 anos, 50 a 59 anos, 60 a 69 anos e de 70 anos em diante. Embora não defina esses percentuais, a lei deixa claro que o valor cobrado na última faixa etária (70 anos ou mais) poderá ser, no máximo, seis vezes superior ao valor da faixa inicial (0 a 17 anos), ou seja, não poderá ser superior a 500\%. Só estão proibidos aumentos por faixa etária para os maiores de 60 anos que estejam no mesmo plano há mais de 10 anos (única exceção) $)^{(33)}$;

b) Contratos firmados a partir de janeiro de 2004: Em 2004, para a adequação ao Estatuto, a ANS aprovou Resolução Normativa n. 63/03, com incidência somente para esses contratos, nos quais não pode haver aumento por mudança de faixa etária para pessoas com 60 anos ou mais em decorrência do disposto pelo Estatuto. No entanto, antes de atingir essa idade o plano pode ser reajustado por faixa etária que passou a ser subdividida em dez ( 0 a 18 anos, 19 a 23 anos, 24 a 28 anos, 29 a 33 anos, 34 a 38 anos, 39 a 43 anos, 44 a 48 anos, 49 a 53 anos, 54 a 58 anos e 59 anos ou mais). Manteve-se o disposto anteriormente, ou seja, o aumento máximo entre a primeira e a última faixa etária não pode ser superior a $500 \%$ e a variação acumulada entre a $7^{\underline{a}}$ e a $10^{\underline{a}}$ faixas não poderá ser superior à variação entre a $1^{\text {a }}$ e a $7^{\text {a }}$ faixas $^{(34)}$.

Isso, no entanto, não garante que o maior incremento ocorra aos 59 anos, ao invés dos 70, como acontecia anteriormente, afugentando os idosos dos planos de saúde e na prática, discriminando-os ${ }^{(35)}$.

Todos os contratos de planos de saúde firmados a partir de 1을 je janeiro de 1999 estão sob a proteção da Lei n. 9.656/98, assim como os contratos de planos de saúde que, embora assinados antes dessa data, foram adaptados às disposições dessa Lei. A maior preocupação refere-se aos planos antigos (contratados antes de 2 de janeiro de 1999 e que não foram adaptados à lei), e que, portanto, não se submetem às regras estabelecidas tendo seus reajustes seguindo os termos nele expressos. Esses não são mais comercializados, mas, seus usuários estão envelhecendo e suas garantias estão descritas, apenas, nas antigas cláusulas contratuais ${ }^{(36)}$.

(32) LAZZARINI, Marilena (Org)., op. cit.

(33) Id. Ibid.

(34) Id. Ibid.

(35) SIQUEIRA, Luiz Eduardo Alves de., op. cit.

(36) BRASIL. Agência Nacional de Saúde Suplementar. Planos de saúde: conheça seus direitos. Reajuste de mensalidade: Conceitos básicos, reajuste por variação de custos, reajuste por mudança de faixa etária, cit. 
Segundo dados da ANS, $11 \%$ do total dos beneficiários de planos de saúde em 2005 tinham 60 anos e mais, enquanto nos planos antigos, 18\% eram idosos ${ }^{(37)}$. Considerando o grupo dos idosos, mais de $56 \%$ pertencem aos contratos antigos. Esses podem levar à discriminação dos idosos a partir do momento em que os impede de se adaptarem às novas regras, em função dos altos preços propostos, definidos em função de seu alto risco.

Conforme o Estatuto do Idoso(38), os cidadãos maiores de 60 anos não podem sofrer reajustes dos planos de saúde. Isso traduz uma política de direitos e de respeito, considerando inclusive que muitos idosos já contribuíram com o plano de saúde por um grande período de suas vidas, habitualmente com baixa utilização. As idades mais avançadas constituem, geralmente, a fase de maior uso dos serviços e, conseqüentemente, de maior custo para o sistema de saúde, o que gera conflitos, principalmente relacionados ao momento de aplicação da referida lei.

Os reajustes permitidos são os relacionados à variação de custos, ou seja, o aumento anual de mensalidade do plano de saúde em razão de alteração nos custos ocasionado por fatores como inflação e uso de novas tecnologias. Há também o reajuste por mudança de faixa etária, que é o aumento decorrente da alteração da idade do consumidor. Esse aumento, em princípio, é justificado em razão do perfil de utilização dos serviços de saúde e riscos diferenciados.

Nos planos novos, o aumento por mudança de faixa etária somente poderá ser aplicado caso estejam previstas, no contrato, as faixas etárias e os percentuais de reajuste incidentes em cada uma delas. No entanto, os consumidores a partir de 60 anos de idade e com 10 anos ou mais de plano, não podem sofrer reajuste por mudança de faixa etária, mas ainda podem ter reajustados seus contratos por variação de custos.

Os planos coletivos não precisam de autorização prévia da ANS para aplicação de reajuste, o que vem trazendo uma preferência das operadoras por esse tipo de plano. Isso poderá diminuir as possibilidades do idoso em adquirir planos individuais por estarem cada vez menos disponíveis e mais caros. Isso poderá ocorrer apesar, e em função, do processo regulatório que ainda não atua de maneira homogênea nesse mercado(39).

Para os planos antigos (assinados antes de 2 de janeiro de 1999), o aumento por mudança de faixa etária somente poderá ser aplicado caso estejam previstas no contrato as faixas etárias e os percentuais de reajustes incidentes em cada uma delas ou se houver autorização do órgão competente.

(37) Brasil. Agência Nacional de Saúde Suplementar. Planos de Saúde, cit.

(38) BRASIL. Lei n. 10.741, de 1. de outubro de 2003. Estatuto do Idoso.

(39) BRASIL. Agência Nacional de Saúde Suplementar. Planos de saúde: conheça seus direitos. Reajuste de mensalidade: Conceitos básicos, reajuste por variação de custos, reajuste por mudança de faixa etária, cit. 
No entanto, após a decisão do Supremo Tribunal Federal (ADIn n.1.931/DF) de 3 de setembro de 2003, não há mais a obrigatoriedade de autorização pela ANS do reajuste previsto no contrato em planos antigos contratados por pessoa física, nem para os consumidores com 60 anos de idade ${ }^{(40)}$.

Esse posicionamento da ANS é discutido pelo IDEC que sustenta que o disposto no Estatuto deve ser aplicado a todos os contratos, independentemente da data de sua celebração. Há, no entanto, algo que é de posicionamento comum a ambos. Trata-se da proibição do reajuste por faixa etária, se este não estiver clara e expressamente contido no contrato (faixas etárias estipuladas e respectivos percentuais de reajuste). No entendimento do IDEC, se esta previsão não estiver expressa, a cobrança do reajuste é ilegal e configura-se como prática abusiva (arts. 6을 III e IV, 46 e 51, X, do Código de Defesa do Consumidor e Portaria n. 3/99 da Secretaria de Direito Econômico do Ministério da Justiça) $)^{(41)}$.

A Justiça não é unânime quanto à aplicabilidade do Estatuto do Idoso aos planos de saúde, cujos contratos foram assinados antes de sua entrada em vigor, no que diz respeito às cláusulas de reajuste por mudança de faixa etária. Isso ocorre em decorrência do que determina o art. 5, inciso XXXVI da Constituição Federal, ao falar de direito adquirido e ato jurídico perfeito, onde se estabelece que as leis somente podem produzir efeito sobre atos que se derem depois de sua entrada em vigor ${ }^{(42)}$.

Segundo o IDEC, existem situações em que, para a proteção da própria relação contratual e dos direitos envolvidos, leis podem recair sobre relações contratuais que se iniciaram antes delas, desde que sejam leis que visem proteger a ordem pública e os interesses sociais. Dessa forma, leis de interesse social, como o Estatuto do Idoso, devem ser de aplicação imediata, incidindo sobre todas as relações que, na execução do contrato de trato sucessivo (como os planos de saúde), acontecerem a partir da edição dessa nova lei. Para vários juristas, o disposto no Estatuto deveria ser aplicado a todos os contratos de planos de saúde, independentemente da data em que foram assinados (antes ou depois da lei), não retroagindo sua aplicação, no entanto, para reajustes anteriores à lei ${ }^{(43)}$.

Ao se abordar a questão do direito, deve prevalecer e manter o foco na proteção social do idoso e seu respaldo legal após a promulgação do Estatuto. Portanto, estes não poderiam ficar sob a lógica do mercado imperfeito que, sob a égide do risco, o medo do custo da saúde e a lógica do lucro, pratica reajustes abusivos a um grupo populacional, nem sempre suficientemente informado para exigir amplamente seus direitos.

(40) Brasil. Agência Nacional de Saúde Suplementar. Planos de Saúde, cit.

(41) LAZZARINI, Marilena (Org)., op. cit.

(42) Id. Ibid.

(43) Id. Ibid. 
Ao contratar um plano de saúde pressupõe-se a contratação de um serviço contínuo onde há um compartilhamento de riscos e uma confiança do consumidor de ter suas necessidades de assistência médica ou hospitalar atendidas, num futuro qualquer, sem surpresas. Trata-se, dessa forma, do estabelecimento de uma relação duradoura, que se estende por anos (contrato relacional ou de trato sucessivo), ou seja, é um contrato (com direitos e obrigações) com prazo indeterminado. Espera-se a garantia e a estabilidade nos custos relacionados que permitam um planejamento e uma previsibilidade, pois, ao envelhecer, quando eventualmente mais precisar, saberá que terá condições de continuar pagando e que sua cobertura assistencial estará garantida.

Assim compreendido, a legislação não pode fixar o consumidor ao momento da assinatura do contrato caso surja, posteriormente a essa data, uma legislação de interesse social, como, por exemplo, o Estatuto do Idoso. Esse é um direito que deve ser inalienável a todo cidadão deste país, em particular à pessoa idosa, que ajudou a construí-lo.

A garantia do acesso aos cuidados de saúde deve existir nas redes pública e privada mediante o fortalecimento das políticas públicas de direito social. Essas redes de atenção à saúde necessitam, por sua vez, adequaremse às necessidades da pessoa idosa, avançando para uma construção de redes intersetoriais, inclusivas, acolhedoras e humanizadas considerando que a ampliação de sua utilização pelos idosos é benéfica no sentido da exigência de sua melhor qualidade.

O sistema de saúde, público e privado, deve oferecer integralidade do cuidado e melhor resolubilidade a um custo mais adequado, buscando a promoção da saúde e a prevenção das doenças e agravos, tendo por princípio um sistema pró-ativo de identificação precoce de riscos e de sinais de fragilidade, com foco na manutenção da capacidade funcional, gerenciamento de doenças crônicas e equipes de referência ${ }^{(44)}$.

O setor de saúde suplementar se depara, assim, com um grande desafio frente à necessidade de reorganizar um modelo de atenção mais voltado ao cuidado integrado das condições crônicas, racionalizar recursos e, ao mesmo tempo, produzir saúde.

Pessoas idosas mais saudáveis, funcionalmente mais independentes e com preservação de sua autonomia podem fazer a diferença, tanto na redução da utilização de serviços de saúde, como na otimização dos gastos.

As políticas voltadas às necessidades do idoso e à garantia de seus direitos precisam continuar a ser construídas mediante um grande pacto nacional. A realização das conferências dos direitos dos idosos e a busca

(44) VERAS, Renato; PARAHYBA, Maria Isabel, op. cit. 
pela implantação da Rede Nacional de Direito ao Idoso (RENADI), em seus vários eixos, são fundamentais para esse avanço. A luta dos idosos e da sociedade, no sentido da preservação do direito de populações vulneráveis, deve avançar para a construção estratégica de possibilidades de implantação das premissas do Estatuto do Idoso, protegendo e permitindo um envelhecimento ativo a todos os brasileiros.

\section{REFERÊNCIAS BIBLIOGRÁFICAS}

BRAGA, Pérola Melissa V. Direitos do idoso de acordo com o Estatuto do Idoso. São Paulo: Quartier Latin, 2005. 287 p.

BRASIL. Agência Nacional de Saúde Suplementar. Planos de saúde: conheça seus direitos. Reajuste de mensalidade: Conceitos básicos, reajuste por variação de custos, reajuste por mudança de faixa etária. 2. ed, Rio de Janeiro: ANS, 2005.

Lei n. 10.741, de 1ำ de outubro de 2003. Estatuto do Idoso.

. Ministério da Saúde. Portaria GM n. 2.528, de 19 de outubro de

2006 - Política Nacional de Saúde da Pessoa Idosa - PNSI.

Ministério da Saúde. Secretaria Executiva. Departamento de Apoio a Descentralização. Coordenação - Geral de Apoio à Gestão Descentralizada. Diretrizes Operacionais dos Pactos pela Vida, em Defesa do Sistema Único de Saúde - SUS e de Gestão. Brasília, 2006.

Portaria do Gabinete do Ministro de Estado da Saúde de n. 1395 de 9 de dezembro de 1999, que aprova a Política Nacional de Saúde do Idoso e dá outras providências. Diário Oficial da República Federativa do Brasil, n 237-E, p. 20-24, 13 dez., seção 1, 1999.

CAIN, Leonard. Direitos do homem e direitos das pessoas idosas. XI Congresso Internacional de Gerontologia, Roma-Itália, 1984. In: FERNANDES, Flávio da Silva. As pessoas idosas na legislação brasileira. São Paulo: LTr, 1997.

CAMARANO, Ana Amélia (Org.). Os novos idosos brasileiros muito além dos 60? Rio de Janeiro: IPEA, 2004. 594p.

CESAR, Chester Luís Galvão; PASCHOAL, Sérgio Márcio Pacheco. Uso dos serviços de saúde. In: LEBRÃ̃O, Maria Lúcia; DUARTE, Yeda Aparecida de Oliveira. SABE - Saúde, Bem-estar e Envelhecimento: o Projeto SABE no município de São Paulo: uma abordagem inicial. Brasília: Organização PanAmericana da Saúde, 2003.

CHAIMOVICZ, F. A saúde dos idosos brasileiros às vésperas do século $X X I$ : problemas, projeções e alternativas. Revista de Saúde Pública, São Paulo, v. 31, n. 2, p. 184-200, 1997. 
DUARTE, Yeda Aparecida de Oliveira; LEBRÃO, Maria Lúcia. O cuidado gerontológico: um repensar sobre a assistência em gerontologia. In: PESSINI, Leocir. Bioética e envelhecimento. São Paulo: Loyola, 2007.

KALACHE, Alexandre; VERAS, Renato; RAMOS, Luís Roberto. O envelhecimento da população mundial: um desafio novo. Revista de Saúde Pública, São Paulo, n. 21, p. 200-210, 1987.

KICKBUSH, I. Foreword. In: EBRAHIM Saul; KALACHE, Alexandre. Epidemiology in old age. London: BMJ, 1996. 316 p.

LAZZARINI, Marilena (Org). IDEC - Instituto Brasileiro de Defesa do Consumidor. Estudo sobre a aplicação do Estatuto do Idoso aos planos de saúde: a questão dos reajustes por mudança de faixa etária. São Paulo: IDEC, 2006.

LLOYD-SHERLOCK P. Ageing, development and social protection: a research agenda. UNRISD Meeting on Ageing, Development and Social Protection, 2002.

MURRAY, C. J.; LOPEZ A. D. Global mortality, disability, and the contribution of risk factors: Global Burden of Disease Study. Lancet, v. 350, n. 9071, p.144, 1997.

ORGANIZAÇÃO MUNDIAL DE SAÚDE. Cuidados inovadores para condições crônicas: componentes estruturais de ação: relatório mundial. Brasília: Organização Mundial da Saúde, 2003.

PALLONI, Alberto; PELAEZ, Martha. Histórico e natureza do estudo. In: LEBRÃO, Maria Lúcia; DUARTE, Yeda Aparecida de Oliveira. SABE - Saúde, Bem-Estar e Envelhecimento: o Projeto SABE no município de São Paulo: uma abordagem inicial. Brasília: Organização Pan-Americana da Saúde, 2003. p. 15-32.

PALLONI, Alberto; PINTO-AGUIRRE Guido; PELAEZ, Martha. Demographic and health conditions of ageing in Latin America and the Caribbean. International Journal of Epidemiology, n. 31, p. 762-771, 2002.

SIQUEIRA, Luiz Eduardo Alves de. Estatuto do idoso de $A$ a Z: idéias e letras. São Paulo, 2004. 238 p.

VERAS, Renato; PARAHYBA, Maria Isabel. O anacronismo dos modelos assistenciais para os idosos na área da saúde: desafios para o setor privado. Cadernos de Saúde Pública, Rio de Janeiro, v. 23, n.10, p. 2479-2489, out. 2007. 